\title{
OS PAITER-SURUÍ E A APROPRIAÇÃO SOCIAL DA TECNOLOGIA, INFORMAÇÃO E COMUNICAÇÃO: DA MEMÓRIA ORAL PARA A MEMÓRIA DIGITAL
}

\author{
THE PAITER-SURUÍ AND THE SOCIAL \\ APPROPRIATION OF TECHNOLOGY, INFORMATION \\ AND COMMUNICATION: FROM ORAL MEMORY TO \\ DIGITAL MEMORY
}

Walace Soares de Oliveira ${ }^{a}$ Marco Antonio de Almeidab

\begin{abstract}
RESUMO
Introdução: Este trabalho se pauta em uma abordagem histórico-sociológica, com o intento de empregar o diálogo conceitual das ciências sociais com os conceitos informacionais na reorganização da cultura da etnia Paiter-Suruí em sua relação com a cultura contemporânea e com o mundo digital. Muito além das permutas e imposições culturais, o imperativo da aquisição pela apropriação social das tecnologias da comunicação e informação (TIC) oportunizou adaptação e resistência cultural dos Paiter-Suruí à sociedade em rede. Objetivo: o trabalho propõe apresentar o processo de transição da memória oral para a memória digital. Metodologia: trata-se de um estudo de caso com levantamento documental do período de 2006, envolvendo o Plano de Gestão da Terra Indígena Paiterey Garah, Etnozoneamento e Transcrições Orais, até os dias atuais, da parceria dos Paiter-Suruí com o Google Inc., além de revisão bibliográfica da ciência da informação, dialogando com as ciências sociais. Resultados: a pesquisa revela o processo de transição cultural pela apropriação social, reflete suas consequências prós, contras e perspectivas. Conclusões: a apropriação social não substituiu a tradição oral Paiter-Suruí. Ampliaram-se as expressões e a mídia digital passou a ser uma de suas apresentações. A preservação da sua cultura continua sendo pela oralidade, porém o compartilhamento virtual com outras culturas os anuncia ao mundo. Suas fronteiras se estenderam para além do território real e sua expansão virtual Ihes permitiu visibilidade e que, agora, sua voz ecoe.
\end{abstract}

Descritores: Apropriação Social. Cultura. Memória Digital. Memória Oral. Tecnologia,

a Doutorando em Ciência da Informação na Universidade de São Paulo (USP). Professor EBTT DE de Sociologia. Coordenador Geral da Rede e-Tec Brasil/IFRO, Direção de Educação a Distância. E-mail: walace.so@usp.br.

b Doutor em Ciências Sociais pela Universidade Estadual de Campinas (UNICAMP). Docente no Programa de Pós-Graduação em Ciência da Informação da Universidade de São Paulo (USP).

E-mail: marcoaa@ffclrp.usp.br. 
Comunicação e Informação (TIC).

\section{INTRODUÇÃO}

Este trabalho se pauta em uma abordagem histórico-sociológica, intentando empregar o diálogo conceitual das ciências sociais com os conceitos informacionais na reorganização da cultura da etnia Paiter-Suruí em sua relação com a cultura contemporânea e com o mundo digital, na perspectiva de novas relações e formações culturais em que os aparatos tecnológicos sejam distintamente apropriados.

Através de levantamento documental e pesquisa de campo, percebe-se esse diálogo conceitual, constatando-se aspectos da apropriação social pelos Paiter-Suruí tanto das Tecnologias da Informação e Comunicação (TIC) quanto de sua inserção e inclusão na sociedade da informação, a sua relação e os impactos em seus processos de preservação e resistência cultural.

A fim de iniciar a discussão da temática em epígrafe, faz-se necessário expor resumidamente as características da região Norte, ainda pouco conhecida pela maioria dos brasileiros. Conhecer um pouco sobre essa região é primordial para a compreensão de sua importância, da sua realidade, dos povos indígenas e tradicionais (quilombolas e ribeirinhos) que a habitam.

A região Norte é a maior região do país e possui o menor índice demográfico e de ocupação registrado. É formada pelos estados do Amazonas, Pará, Acre, Rondônia, Roraima, Amapá e Tocantins. Apresentar suas características implica em nortear o leitor na peculiaridade da construção social e cultural, bem como das relações dos indígenas com a floresta, sua visão holística dessa relação e sua influência na construção cultural. Além disso, tal apresentação é necessária para introduzir o leitor em uma reflexão sobre como - contato das diferentes culturas impacta as relações socioculturais, constituindo-se de tão diversas referências e perspectivas.

A atual conjuntura em relação às comunidades indígenas, derivada da sua adaptação pós-contato com a cultura dominante do "homem civilizado", confere novas organizações, significados e representações acerca da compreensão do 
real e das adaptações culturais. $O$ arcabouço de referências, sentimentos e representações que as comunidades indígenas possuíam com a floresta e sua relação sociocultural se reorganizaram posteriormente a esse fenômeno.

As comunidades indígenas que vivem na região têm como particularidades a tradição oral em construções, concepções simbólicas e empíricas da sua compreensão da floresta, do real, de identidade cultural e das representações de pertencimento. O pós-contato e a convivência com o "homem civilizado" impuseram às etnias indígenas uma drástica transformação, obrigando-as a buscar ajustamento ao novo processo de relação com o "homem civilizado", que foi inserido em seu cotidiano, e às alterações ocorridas em seu entorno.

Esse processo não é uma simples troca, pois é complexo e doloroso. Além de todas as dificuldades inerentes ao ajustamento cultural, os indígenas se encontram, concomitantemente, diante de outro processo adaptativo: a nova sociedade global em rede. A configuração contemporânea impõe uma sociedade em rede para todos e não consente que nem mesmo as comunidades indígenas fiquem isoladas, seja do "contato real", seja do "contato virtual". Por mais precário que seja o acesso à internet e às TIC, tais procedimentos estão presentes nas atuais relações e modificações da nova relação social indígena.

Nesse sentido, é imperioso o incentivo a estudos e pesquisas científicas que envolvam as etnias de Rondônia. A presente pesquisa se dá com a etnia Paiter-Suruí de Rondônia, considerando-se o processo de apropriação social das TIC, a consequente transição e impactos na tradição e cultura oral para a inserção da cultura digital na sociedade. Um dos pontos fundamentais desta pesquisa se refere à preservação, manutenção e adaptação da cultura e da memória oral dos Paiter-Suruí à nova proposta da sociedade da informação, buscando compreender os fenômenos gerados por essa relação.

\section{CARACTERÍSTICAS REGIONAIS}

A floresta amazônica se caracteriza, quase em sua totalidade, por compor, geograficamente, a maior parte da Amazônia Legal. Sua característica 
climática é mesclada pelos climas equatorial e tropical, porém o clima predominante é o equatorial, com elevadas temperaturas e umidade durante todo o ano. O "verão amazônico" é marcado pela seca e o "inverno amazônico" é o período das chuvas. A água permeia praticamente todas as relações amazônicas.

A logística da região amazônica é peculiar e a oferta de estradas é pequena, considerando-se sua extensão e geografia. Os rios são seus principais "caminhos", tanto para as comunidades indígenas, povos tradicionais, quanto para aqueles que moram nos centros urbanos. As estradas entre os estados e no interior dos estados são precárias, sobretudo no chuvoso inverno amazônico. A malha viária, em sua maioria, se constitui de estradas de terra e as asfaltadas têm um enorme déficit de manutenção.

No final do século passado, foi concretizada grande parte da política de demarcação de terras e reservas na região, todavia os conflitos ainda persistem na atualidade. $O$ número de garimpos clandestinos, a exploração madeireira ilegal, o litígio de terras entre invasores (grilagem), as evangelizações discriminadas e a expansão do agronegócio (gado e soja) - que tenta destituir as etnias indígenas de suas reservas já demarcadas ou em processo de demarcação - avançam em passo acelerado sobre a floresta.

Alisson (2018) da Agência FAPESP (Fundação de Amparo à Pesquisa de São Paulo), publicou, em fevereiro de 2018, uma reportagem com dados do editorial do periódico Science Advances, tendo como base o artigo de Thomas Lovejoy, professor da George Mason University, nos Estados Unidos, e Carlos Nobre, coordenador do Instituto Nacional de Ciência e Tecnologia para Mudanças Climáticas - um dos INCT apoiados pela FAPESP, no Estado de São Paulo, em parceria com o Conselho Nacional de Desenvolvimento Científico e Tecnológico (CNPq). Esse estudo reflete as consequências do desmatamento da região amazônica e seus desdobramentos.

Tanto o editorial quanto o artigo apresentam estudos do impacto do desmatamento sobre o ciclo hidrológico amazônico e suas consequências. Esse movimento põe em risco todo o equilíbrio do ecossistema da floresta tropical, alertando seu limite e que, ao atingir o nível de $25 \%$, o desmatamento terá 
consequências irreversíveis para a floresta, corroborando a real situação descrita sobre os conflitos da região e seus desdobramentos.

Essa é uma análise inquietante, porém real, da situação e de seus desdobramentos socioambientais, o que já é amplamente discutido pelas pesquisas da comunidade científica sobre as ações humanas e seus efeitos climáticos nas últimas décadas.

Essas são as marcas da relação belicosa existente na região. $O$ acirramento é balizado pela falta de políticas públicas, de infraestrutura e de fiscalização adequada na área ambiental, além de descaso do poder público em relação às políticas públicas para os povos indígenas e tradicionais.

A displicência dos gestores públicos pelo tema, evidenciada por suas atitudes, produz efeitos como a aceleração do processo de aquecimento climático, o desequilíbrio das chuvas e o consequente desabastecimento de água em outras regiões do país. Nesse sentido, a região Norte é fundamental para o todo o planeta Terra, em decorrência de seu sistema de chuvas e evapotranspiração ${ }^{1}$ - fenômeno diretamente ligado ao equilíbrio do ecossistema

1Cerca de $70 \%$ da quantidade de água das chuvas sobre a superfície terrestre retorna à atmosfera pelos efeitos da perda de água do solo por evaporação e perda de água da planta por transpiração. A evapotranspiração nada mais é que a soma desses dois fenômenos, fundamentais ao ciclo da água em todo o planeta.

A evaporação é responsável pelo movimento da água para o ar a partir de fontes como o solo, dossel florestal e corpos d'água, como lagos, córregos, rios e mares. A água recebe calor solar e aquece até que atinge seu ponto de ebulição. A partir daí o calor não eleva mais a temperatura da água; ele age como calor latente de vaporização e converte a água do estado líquido para o gasoso. Esse vapor d'água se liberta do líquido e passa a compor a atmosfera, situando-se nas camadas mais próximas da superfície.

A transpiração representa o movimento da água dentro de uma planta, e a consequente perda da mesma para a atmosfera. As plantas, para desempenhar suas necessidades fisiológicas, retiram a água do solo através de suas raízes, retêm uma pequena fração e liberam o restante através de microscópicas válvulas presentes nas superfícies das folhas (os estômatos), sob forma de vapor d'água. O conhecimento da água perdida por evapotranspiração é fundamental para se conhecer o balanço hídrico de uma certa região. Ela afeta diretamente o rendimento de bacias hidrográficas, a umidade atmosférica, a determinação da capacidade de reservatórios, regime de chuvas, entre outros. A evapotranspiração é melhor percebida em ambientes onde esses dois processos ocorrem simultaneamente: em solos com cobertura vegetal é praticamente impossível separar o vapor d'água proveniente da evaporação do solo daquele originado da transpiração das plantas.

Diferentes ambientes apresentarão diferentes taxas de evapotranspiração, uma vez que ela é afetada por vários fatores, como: estágio de crescimento da planta crescimento ou nível de maturidade, tipo de folha, a porcentagem de cobertura vegetal do solo, radiação solar, umidade, temperatura e o vento. A taxa de evapotranspiração da floresta será muito maior do que qualquer 
regional, do país e global. Enfoca-se, aqui, a relação ambiental, que é fundamental para a presente pesquisa, dadas as características das comunidades indígenas; dessa forma, não serão abordados outros aspectos que compõem a realidade da região.

Ressalta-se que, segundo os relatos das comunidades indígenas e de diversas ONG ligadas à preservação ambiental, a perspectiva do novo governo, desde a campanha eleitoral de 2018 à presidência da república, instigou ainda mais os ânimos com a ideia de que políticas ambientais e a região Norte terão outra concepção de exploração, contribuindo significativamente para o aumento dessas atitudes, mantendo as comunidades indígenas e tradicionais em constante estado de apreensão e vulnerabilidade social.

É necessário, portanto, refletir sobre alguns processos que se estabelecem na relação da transformação sociocultural de algumas etnias após o contato e inserção na sociedade. Essas são questões relevantes, que devem ser levantadas e debatidas na atualidade, para se compreender a integração ou tentativa da proposta de uma relação entre as comunidades indígenas e a sociedade atual de forma harmoniosa.

\section{OS PAITER-SURUÍ}

Os indígenas Paiter-Suruí habitam os postos indígenas Sete de Setembro e Quatorze, no Município de Cacoal. A reserva indígena Sete de Setembro ocupa terras de Rondônia e Mato Grosso, no chamado Cone Sul.

O estado de Rondônia teve contato com diversas etnias desde muito antes dos antigos territórios da Ditadura Militar se terem transformado em estados. Porém, somente após o projeto da rodovia Transamazônica, no mesmo

cultivo ou pastagem, mas modificações no uso do solo, geralmente implicam em mudanças no fluxo de vapor de água para a atmosfera e, consequentemente, no ciclo da água.

Por exemplo, o desmatamento e a exploração madeireira diminuem a quantidade de água que a vegetação libera para a atmosfera (evapotranspiração) e, consequentemente, reduz o volume das chuvas. Com a redução do volume de chuvas, há maior possibilidade de ocorrência de incêndios florestais que, por sua vez, provocam a mortalidade de árvores. Esses incêndios e as queimadas em campos agrícolas e pastagens produzem fumaça que interfere nos mecanismos de formação das nuvens e também dificultam a ocorrência de chuvas. DICIONÁRIO (2014) 
período em que as fronteiras se expandiram para o norte do país, os contatos se intensificaram. Segundo Trubiliano e Ferreira (2018), o primeiro contato oficial da etnia Paiter-Suruí ocorreu da seguinte forma:

Especificamente o povo Paiter Suruí o contato oficial ocorreu com a Fundação Nacional do Índio (FUNAI) em setembro de 1969. Entretanto, os Paiter Suruí já estavam em conflito com os colonos desde o início da década de 1960. Segundo as pesquisas de Chicoepab Suruí (2013), nos primeiros anos do contato, a população que ultrapassava 5.000 pessoas foi reduzida para aproximadamente 250 indígenas. A mortalidade ocorreu, principalmente, devido a doenças infectocontagiosas como sarampo, gripe e pneumonia. Diante desse cenário de extermínio étnico, os valores tradicionais, simbólicos e culturais dos Paiter Suruí encontravam-se ameaçados (TRUBILIANO; FERREIRA, 2018, p. 206).

A denominação Suruí foi herdada dos antropólogos responsáveis pelo primeiro contato, contudo a preferência dos indígenas é utilizar seu nome original, Paiter, que significa "nós mesmos, o povo verdadeiro", autodenominando-se Paiter-Suruí. A língua empregada por eles pertence ao Tronco Tupi, da família linguística Mondé. Para preservá-la, a língua é ensinada nas escolas do território indígena. A unidade de diversos povos na região, que falam o Tupi-Mondé, estabelece o projeto de formar um corredor etnoambiental Tupi-Mondé, com o objetivo de se organizarem nas demandas para os órgãos oficiais (COORDENAÇÃO DAS ORGANIZAÇÕES INDÍGENAS DA AMAZÔNIA BRASILEIRA, 2013).

Pucci (2009) ressalva que não aceitar a denominação Suruí também se dá pelo sentimento de pertencimento e identidade. Essa etnia pertence ao tronco linguístico Tupi-Mondé e se distingue dos Suruí do Pará, etnia do tronco TupiGuarani, com diferenças linguísticas e culturais.

Segundo Melo, Silva e Suruí (2015), a marca do contato entre os PaiterSuruí e o "homem civilizado" determinou um processo de transformações em sua cultura, resultando na aquisição de representações que não lhes pertenciam e na reorganização de suas representações internas, mesmo com a manutenção de sua referência cultural e cosmogonia. Em relação a esse processo de contato e ocupação de culturas tão divergentes na relação com a floresta, Galvão (1979 apud MELO; SILVA; SURUÍ, 2015) salienta: 
A "ocupação" desses territórios foi marcada por conflitos, dos quais alguns deles ainda em evidência, o que caracteriza o que Galvão (1979) qualifica como "encontro de sociedades", ou seja, distintas culturas humanas com distintas apreensões e visões de mundo, o que inclui a compreensão sobre a utilização da natureza (GALVÃO, 1979 apud MELO; SILVA; SURUÍ, 2015, p. 41).

O encontro de culturas divergentes impacta os diferentes olhares de cada uma e suas relações estabelecidas com o real. Diferente do conceito que tem o "homem civilizado", a floresta é mais que um patrimônio para os Paiter-Suruí: a floresta é a própria vida. A convivência entre ambas as culturas concretiza novas relações de forma lenta. Um lado sempre se impõe sobre o outro e o legado do conflito precisa ser organizado e superado pelo lado que sofreu a imposição.

\section{MEMÓRIA E TRADIÇÃO ORAL}

A geração Paiter-Suruí do contato inicial não falava a língua da sociedade ocidental, não conhecia os seus conceitos de trabalho ou os meios de produção, não tinha a sua noção de propriedade, não apresentava a mesma estrutura religiosa, nem a sua construção do conhecimento e do conceito de informação, bem como seus processos informacionais. Aliás, ela é marcada pela oralidade e uma carga simbólica muito forte com particularidades na constituição daquilo que se conhece por memória.

A cultura do "homem civilizado" se caracteriza pelo domínio da escrita e pela organização da sociedade em relação à estrutura, conhecimentos e relações que se estabelecem ao longo de sua história. Marcada pela escrita, a sua memória organiza diferentes fatores no que diz respeito à expressão e significados. Seus conceitos de memória e informação, portanto, são muito diferentes das culturas indígenas. Enfim, indígenas e não indígenas são culturalmente divergentes e se encontram numa relação de conflito; suas peculiaridades são importantes para a compreensão da apropriação social que se estabelece de cada um desses lados.

Para Le Goff (1990), a ideia de memória é de suma importância e tem profunda ligação com as ciências humanas, principalmente com a história e a antropologia, constitui um forte atributo em relação à memória coletiva sobre a 
individual, sem deixar de conferir a importância da última, e com o predicado de cultivar as informações de outrora; assim, a memória tem relação com várias outras ciências.

Ribeiro (2019) confere uma relação essencial entre a memória e informação em sua representação. O termo é usado tanto no singular como no plural, com caráter multifacetado e polissêmico, constitui um processo de construção e reconstrução. A memória é baseada no compartilhamento de lembranças e discursos de fatos com impactos individuais e coletivos, com forte apelo emotivo, é seletiva e orgânica. Ademais, ela tem um caráter de construção social.

As comunidades indígenas têm na tradição oral sua base de organização do imaginário, do simbólico e da expressão do real. Seus mitos, sentimentos e significados se dão através de narrativas construídas a partir de sua relação com a floresta. Tudo isso é transmitido em suas narrativas, seus cânticos e poemas, tendo a oralidade como sua grande expressão.

A escrita, como a utilizamos, Ihes era desconhecida tradicionalmente, mas está presente em seus grafismos da cerâmica, pinturas corporais, tatuagens, utensílios e outras formas de significados. Somente após o contato os povos indígenas se apropriaram da escrita, entretanto, justamente pela relação imposta, pode-se considerar a escrita como uma marca de dominação nessa relação conturbada.

Ribeiro (2019) ressalta que "memória" está atrelada à "informação" e tem uma conotação conceitual estreita com a ciência da informação em seu cerne, cada vez mais evidenciada. O processo do produto dessa memória, seja um registro escrito ou oral, tem suas singularidades: as culturas escritas organizam o registro em documentos guardados em acervos ou bibliotecas; as culturas orais organizam o registro em seu imaginário coletivo, transmitido em narrativas, canções ou mitos.

Os anciãos e os pajés eram aqueles que detinham as diversas memórias relacionadas a toda tradição indígena e sua relação com a floresta, bem como tinham a responsabilidade de preservá-las e compartilhá-las através dos ritos, das iniciações, das festas, dos cânticos, dos poemas e das curas. A prática da 
oralidade se dava em todo o cotidiano, não somente em eventos especiais. O dia-a-dia, marcado pelas atividades mais simples, tem a sua função na memória coletiva, assim como os momentos especiais de rituais e festas.

Calvet (2011) propõe que, levando-se em conta a comunicação linguística e tendo como referência a oralidade e a escrita, duas configurações de sociedades foram produzidas: as sociedades de tradição oral e a as sociedades de tradição escrita. Na sociedade ocidental de tradição escrita, a memória, a história e a informação têm uma outra relação, estão organizadas pelo que se chama de conhecimento; em decorrência, as sociedades de tradição oral, olhadas de maneira etnocêntrica, são colocadas como culturas inferiores e marginalizadas.

Calvet (2011) ressalva que os termos "sociedades de tradição oral" e "sociedades de tradição escrita" são limitadores e não apresentam todo o espectro. Tais termos apenas determinam as "fronteiras" das possibilidades de compreensão da sua diversidade. Assim, o autor propõe a seguinte classificação:

(1) as sociedades de tradição escrita antiga, nas quais a língua escrita é aquela que se utiliza na comunicação oral cotidiana (com as diferenças óbvias entre o oral e o escrito). É o caso da maioria das sociedades europeias atuais, nas quais 0 analfabetismo é raro, quando não completamente extinto.

(2) as sociedades de tradição escrita antiga, nas quais a língua escrita não é aquela que se usa na comunicação oral cotidiana. É o caso, por exemplo, dos países árabes (onde se escreve o árabe clássico, mas se fala o árabe dialetal), nas quais o analfabetismo é mais presente do que nas sociedades do primeiro tipo.

(3) as sociedades nas quais se introduziu recentemente a prática alfabética, em geral pela via de uma língua diferente da língua local, é o caso dos países que foram colônia na África e na América Latina, aos quais se impôs uma picturalidade (o alfabeto latino) proveniente da herança cultural colonial.

(4) as sociedades de tradição oral. [...] a ausência de tradição escrita não significa, de maneira alguma, ausência de tradição gráfica. Em muitas sociedades de tradição oral, existe uma picturalidade muito viva, nas decorações de potes e cabaças, nos tecidos, nas tatuagens e nas escarificações etc., e mesmo que sua função não seja, como no caso do alfabeto, registrar a fala, ela participa da manutenção da memória social (CALVET, 2011, p. 11). 
$\mathrm{Na}$ tradição oral, o papel do narrador/contador que representa as culturas indígenas é resguardado pela memória dos mais velhos, que são os detentores da vivência e conhecimento vivo da relação e dos acontecimentos. Sua presença é fundamental para a transmissão, visto que os mais velhos são a memória coletiva viva. Nesse sentido, na tradição oral, a variedade permanece, os conteúdos se transformam, mas a forma é preservada. Não há a rigidez de conteúdo e forma que se distinguem, como na tradição escrita.

Tomando-se como base a classificação de Calvet (2011), nota-se que, no Brasil, as comunidades indígenas estão entre o terceiro e o quarto grupo. Especificamente, os Paiter-Suruí se encontram num processo de transição da oralidade para a escrita, produzindo a sua própria "escrita" através da educação indígena nas escolas bilíngues que mantêm em sua reserva. Essa é uma construção, entre as muitas impostas pela relação com o "homem civilizado", em sua adaptação à sociedade formal.

A transferência oral dos fatos ou eventos das culturas indígenas está balizada por processos de memorização e improvisação. Para Calvet (2011), o estilo da oralidade apresenta variações: cada narrador, ao narrar uma ocorrência para os ouvintes, busca a compreensão, procurando, no estilo oral (narrativa ou cântico), facilitar esse processo, mostrando que sua retransmissão é artística, sintática, de tom, com dicção própria para sua transmissão e é sempre uma recriação que preserva a forma fidedigna.

A memória das comunidades indígenas é diferente de nosso conceito de memória. Tanto o tempo passado quanto o presente se encontram numa relação para significar e compreender, de forma circular, os repertórios e novos sentidos de seus rituais, continuamente reproduzidos a exaustão de sua vivência e transmissão. Todo evento expressivo é marcado por um significado e contado sempre para lembrar e manter a memória viva, na forma de suas narrativas, cânticos, ritos ou poemas.

Assmann (2011) ressalta a reflexão conceitual entre memória e história na cultura escrita e propõe uma leitura de ambas como modos de recordação de um processo. Nesse contexto, o referido autor estabelece dois modos complementares de recordações ligadas ao conceito de memória: a memória 
habitada e a memória inabitada. A memória habitada é funcional, liga passado, presente e futuro, pertence à referência grupal e de identidade e é seletiva. A memória inabitada, porém, apesar de ser cumulativa e equivaler a memória histórica, possuindo a representação de reservatório das memórias funcionais, não é natural e necessita de um apoio para ser preservada. Contudo ambas se complementam, sem a necessidade de uma dicotomia rígida.

A memória histórica ou cumulativa tem suporte no movimento de separação do passado, presente e futuro, não depende do grupo e não é seletiva, porém é igualmente importante. Assim, ao associar a memória funcional, a memória coletiva denomina-se memória habitada, diferente da memória funcional, que pode ser alterada e utilizada de várias maneiras. Destacam-se, assim, três usos: a legitimação e a deslegitimação - que podem alterar a memória, tanto confirmando quanto anulando por fins específicos - e a distinção, que envolve os meios alegóricos construtivos da identidade coletiva.

Assmann (2011) se refere à memória cumulativa, relacionada às ciências históricas, como "uma memória das memórias, que acolhe em si aquilo que perdeu a relação com o vital, com o presente" (ASSMANN, 2011, p. 147). É o local das lembranças que está na fronteira da memória funcional, é a "massa amorfa". O referido autor faz a analogia de um modelo com dois planos: "proscênio e pano de fundo", buscando, dessa maneira, um caráter de perspectiva e não dualista, com funções específicas, mas integradoras, um no papel daquilo que é mais relevante e fica evidenciado por aquilo que é menos relevante e tem a função de suporte.

$\mathrm{Na}$ cultura escrita, o conceito de memória é relacionado à história, observando-se que a memória pode ser usada como uma fonte da história, porém não é a história. A memória escrita tem também uma relação com o documento e o registro, que está relacionado com a história.

Segundo Assmann (2011), essa relação estabelece a organização da seletividade para que a memória funcional utilize a memória cumulativa como "recursos auxiliares livres". Portanto, "esses recursos mantêm ao dispor um saber adicional que, como memória das memórias, pode garantir que memórias funcionais realmente dadas possam ser criticamente relativizadas ou, ainda 
renovadas ou transformadas" (ASSMANN, 2011, p. 150), propiciando um "pano de fundo (estabilizador ou corretivo) para operações que, quando necessárias, auxiliam na fundamentação de valores.

As culturas orais não fazem distinção entre memória funcional e memória cumulativa. Essa é uma distinção presente nas culturas escritas. Segundo Assmann (2011):

\begin{abstract}
Esses mecanismos derivados da observação da memória individual podem ser transpostos para a memória cultural. Em uma cultura oral da memória, na qual memórias individuais fortalecidas por esteios materiais e corpóreos como bordadura, pintura, ritmo, dança e música constituem o refúgio da memória cultural, é impensável haver distinção entre memória funcional e cumulativa. Há pouco lugar na memória e as técnicas de memorização são tão dispendiosas que não entra sequer em questão conservar algo que também seja útil para a identidade do grupo e, portanto, decisivo para sua sobrevivência. Com a escrita, por outro lado, enquanto medium cumulativo paradigmático extracorporal, ultrapassa-se esse horizonte das culturas orais da memória. Com a escrita pode-se registrar e acumular mais do que se poderia evocar por meia da recordação. Com isso, distende-se a relação entre recordação e identidade; a diferença entre memória cumulativa e funcional está embasada nessa distensão (ASSMANN, 2011, p. 150).
\end{abstract}

Nesse sentido, pode-se notar que, na cultura escrita, diferente da cultura oral, a informação tem um outro caráter em sua relação com a memória, bem como a sua produção e compartilhamento. Diferente das culturas orais, a cultura escrita produz uma quantidade atualmente incomensurável de informações e documentos vinculados à memória e possui, no seu armazenamento, compartilhamento e gestão, um conjunto de importantes fatores e características.

\title{
5 A APROPRIAÇÃO SOCIAL DAS TIC
}

Almir Narayamonga Suruí, um dos líderes Paiter-Suruí, em uma fala emblemática e divulgada posteriormente, propôs o seguinte desafio para 0 Google, em relação ao Projeto de Carbono Suruí: "Vocês podem entender tudo de tecnologia, mas não entendem nada de floresta, por isso, nós ensinamos vocês sobre as florestas e vocês nos ajudam a proteger as florestas com 
tecnologia". No ano de 2006, constituiu-se a proposta de parceria do Google com o Projeto de Carbono Florestal Suruí.

Ao tomar conhecimento do projeto de preservação e sustentabilidade da floresta, o Google disponibilizou, junto ao departamento Google Earth, através de sua gerente Rebeca Moore, uma proposta de desenvolvimento tecnológico e capacitação via oficinas, com ferramentas que permitiram a possibilidade de um novo estágio de defesa no preparativo dos Paiter-Suruí para sua inserção digital e seu protagonismo social.

Pereira (2007, apud ROMERO, 2013) já ressaltava sobre o início da utilização da web pelos indígenas brasileiros, em 2001, via sites, blogs e outras ferramentas. Porém, o primeiro evento relacionado a essa ferramenta e às culturas indígenas se institucionalizou em 2010, com o $1^{\circ}$ Simpósio Indígena sobre os usos da Internet no Brasil, organizado com suas lideranças, ocasião em que foram feitas as primeiras reflexões a respeito dessa tecnologia e suas influências no modo de vida indígena.

Como tudo o que envolve as culturas indígenas em sua relação com o "homem civilizado" e suas consequências, não houve uma concordância, entre as etnias participantes, sobre os usos dessa nova tecnologia e sua eficácia. Como naquele período muitas etnias não tinham acesso ou conhecimento da tecnologia, não se chegou a um consenso. Alguns anos e maior experiência por parte de outras etnias foram necessários para as opiniões convergirem. Segundo Belton (2010 apud ROMERO, 2013, p. 04), para serem ouvidos, "os povos originários da América utilizam dois espaços no mundo globalizado para articular suas lutas e fazer ouvir a sua voz: o Ciberespaço e o Foro Permanente para as Questões Indígenas da ONU". Assim, a web funciona, até hoje, como canal de visibilidade que as culturas indígenas não dispõem nos meios tradicionais e o Foro Permanente da ONU, seu último local de apelo.

Como participantes do $1^{\circ}$ do Simpósio Indígena sobre usos da internet no Brasil, os Paiter-Suruí trouxeram contribuições, pois já faziam a utilização da ferramenta e solidificavam uma parceria com o Google. A adaptação não foi a incorporação pura e simples da tecnologia, seus instrumentos ou cultura do "homem branco", pois há em curso um processo de apropriação da tecnologia, 
processos informacionais, organização do conhecimento, instrumentalização e compartilhamento da informação.

Romero (2013) se refere a esse processo com um breve relato histórico sobre as fases antecedentes à afinidade dos Paiter-Suruí com a web:

Antes de explorar esse tema, torna-se necessário conhecer a realidade histórica dos Paiter Suruí, que passou por três fases históricas bem demarcadas, conforme relatadas no próximo item. Na primeira, antes do contato, os indígenas mantinham uma estreita relação com a floresta. Na segunda fase, com o contato e invasões dos não indígenas, deixaram de preservar os recursos naturais do seu território e começaram a vender madeira ilegalmente para conseguir dinheiro. $\mathrm{Na}$ terceira e última fase, a partir dos anos 2.000 , as novas lideranças compreenderam a importância de proteger a floresta e voltaram a ter uma forte relação com a natureza (ROMERO, 2013, p. 05).

Dessa forma, os Paiter-Suruí passaram a ser reconhecidos como os "índios da internet". Organizados e conectados, eles criaram um Parlamento Paiter, estabeleceram uma política de sustentabilidade, preservação ambiental da floresta e negociam internacionalmente pelo seu Projeto Carbono Suruí. A sua história não é mais contada por terceiros, visto que assumiram a condição de narradores de sua cultura para o mundo ao compreender as novas fronteiras ditadas pela tecnologia da informação.

Em relato pessoal, Almir Narayamonga Suruí - uma das vozes que emergiram das comunidades indígenas durante esse período ligado à preservação do meio ambiente e estabelecimento de uma nova relação de defesa da cultura indígena - afirma que a parceria possibilita um novo momento de luta e visibilidade sobre a questão amazônica.

Segundo Romero (2013), o desenvolvimento da proposta seguiu-se da seguinte maneira:

Mediante o Google Earth foi possível definir os limites da Terra Indígena Sete de Setembro cartograficamente. Além disso, os mapas permitiram uma identificação das áreas devastadas da Amazônia, o que permite, por sua vez, observar as invasões no seu próprio Território. Dessa forma, os Paiter Suruí usam o Google Earth como uma ferramenta de proteção ambiental e de prevenção contra as invasões das madeireiras, posseiros e de todo tipo de ameaças. O discurso proferido pelo chefe Almir Narayamonga Suruí, em várias partes do mundo, chama a atenção para a ameaça do aquecimento global e afirma que, partindo de um meio de comunicação como Internet, os povos 
indígenas esperam contribuir para manter a "floresta em pé", trazendo assim qualidade de vida e benefícios não só para quem vive na floresta como também para toda a humanidade. Assim, por meio das palavras do líder maior dos Paiter Suruí, pode-se constatar a importância atribuída a utilização da tecnologia por parte dos indígenas numa luta com interesses globais (ROMERO, 2013, p. 10).

Romero (2013) descreve como a memória oral e as informações que estavam organizadas na memória coletiva, com eventos relevantes como o local do primeiro contato, os territórios de caça, pesca e das coletas, locais das primeiras guerras e eventos que marcaram a história e identidade dos PaiterSuruí, passaram pelo processo de Georreferenciamento com a parceria e foram organizados na ferramenta Mapa Cultural disponível no site http://www.paiter.org. Consequentemente, a cultura está preservada e apresentada para todos via web.

As transformações são significativas e a apropriação social das TIC é evidenciada nessa ação. Segundo Romero (2013):

Tecnologias como o GPS são usadas pelos indígenas para defender o seu território do desmatamento. Após o treinamento, os indígenas são divididos em grupos, que passam até cinco dias na floresta observando qualquer movimentação estranha ou invasão. Com a ajuda do GPS enviam os dados do posicionamento dos invasores para a FUNAI e para a Polícia Federal, para que efetuem a detenção dos madeireiros ilegais. Mediante a Associação Metairelá, criada pelos próprios indígenas Paiter Suruí, impulsionou-se o projeto de educação indígena Ponto de Cultura Maloca Digital. O objetivo desse projeto é fortalecer a autonomia e educação dos próprios indígenas. Em desenvolvimento desde 2010, no distrito de Riozinho, nesse Ponto de Cultura se realizam as aulas de Linux, Multimídia, fotografia e vídeo para jovens indígenas. Para Almir Suruí, a finalidade desse projeto é "levar as tecnologias da informação e da comunicação para as aldeias indígenas, preparando os jovens indígenas para contribuir na preservação da cultura e biodiversidade, para melhorar o intercâmbio entre todos os povos" (PONTO DE CULTURA MALOCA DIGITAL, 2012). Exatamente o que estão fazendo os Paiter Suruí é aproveitar as tecnologias da informação para que o mundo conheça a sua cultura e, ao mesmo tempo, utilizar essas tecnologias em favor dos seus objetivos políticos e preservação da Amazônia (ROMERO, 2012). Com a aproximação das distâncias, através da sociedade atual, que está conectada em rede em escala global, reordena-se o tempo e o espaço, para gerar novos processos que transformam a sociedade. Alguns chamam de globalização, já que graças às tecnologias da 
informação, esse processo abre canais de comunicação e atravessa fronteiras, modificando culturas e identidades, gerando novas formas de democracia e de participação (CASTELLS, 2006 apud ROMERO, 2013, p. 11).

O Projeto Carbono Suruí é uma realidade e se mostra como uma opção em sintonia com as propostas de preservação ambiental mundial e de combate ao aquecimento global. Muito de seu sucesso está atrelado à referência cultural que os Paiter-Suruí têm na sua relação com a floresta e na opção de manter tanto a tradição, quanto o seu local de nascimento, o que lhes dá o sentimento de pertencimento e identidade. Esse processo se dá pela apropriação social de fato. Romero (2013) assim expõe sobre a legitimidade e importância do Projeto Carbono Suruí:

O "Plano de Gestão 50 anos do Povo Paiter Suruí" tem como objetivo aumentar a renda dos indígenas e o nível educativo, além de preservar a floresta e a sua cultura. $O$ projeto de Carbono Florestal Suruí, que faz parte do Plano, foi validado em 201210 sob o Padrão de Carbono Verificado (VCS) e o Padrão Ouro de Clima, Comunidade e Biodiversidade (CCB), que são os principais padrões para creditar projetos que visam reduzir as emissões de gases do efeito estufa do desmatamento e degradação florestal, um conceito conhecido como REDD. A iniciativa dos indígenas evitou que quase 205 mil toneladas de dióxido de carbono fossem emitidas na atmosfera pelo desmatamento entre 2009 e 2011 (ROMERO, 2013, p. 11).

Em contrapartida, Hjarvard (2014) argumenta que a apropriação social também é paradoxal, pois, num conceito pós-moderno, as relações estão ligadas à midiatização do habitus. Afinal, a apropriação social é quem dialoga sobre a tecnologia, sua apreensão e impactos, refletindo como essa relação se estabelece e influencia os atores sociais e suas relações. Portanto, a utilização da tecnologia está diretamente ligada às mudanças das relações estabelecidas.

Hjarvard (2015) propõe uma reflexão teórica sobre a atual sociedade e seu processo de passagem da mediação para a midiatização. Afinal, com as novas mídias e a teoria da midiatização, busca-se compreender como a sociedade atual e suas referências são impactadas no processo midiático. Salienta-se que a sociedade atual se reordena sob essa referência. Portanto, as novas mídias, ao influenciarem a cultura e sociedade, reestabelecem novos conceitos e padrões.

De acordo com Hjarvard (2015), comunicar sempre foi imprescindível ao 
ser humano que, ao longo de sua história, criou meios e instrumentos de comunicação. Quando organizou a comunicação e suas formas de interação, o ser humano estabeleceu a mediação referente às relações específicas em tempo e espaço. Os meios tradicionais estão se transformando na pós-modernidade, mas, primordialmente, a relação entre emissores e receptores também é alterada, na atualidade, nesse novo espaço. Assim, ao refletir sobre as influências das atuais transformações midiáticas, exercita-se a reflexão sobre as modificações das relações culturais e da sociedade.

Segundo Hjarvard (2015), ao se refletir sobre a midiatização, busca-se a compreensão do processo estrutural da mídia, em longo prazo, na atual cultura e sociedade. É necessário compreender todo a reciprocidade e seu envolvimento nas transformações do espectro da comunicação de forma total: emissor, mensagem e receptor. Só assim se pode visualizar suas influências de alteração estrutural nas relações de troca, nas relações sociais, nas relações culturais, enfim, em todas as relações produzidas na atualidade, seus respectivos meios e ferramentas para essa construção.

Para tanto, Hjarvard (2015) afirma que é necessária, ainda, a compreensão da mediação, que se refere à forma como se age na relação da mídia enquanto estabelecimento comunicacional de interação. A midiatização é a relação dos padrões que irão se alterar numa perspectiva institucional e na relação dos atores sociais, influenciando também os novos padrões que irão se estabelecer sobre a comunicação mediada. Todas essas situações, procedimentos e impactos estão presentes na apropriação social dos PaiterSuruí na construção da sua relação cultural e social na atualidade

\section{CONSIDERAÇÕES FINAIS}

Os Paiter-Suruí, em sua apropriação social, estabeleceram a midiatização, que é uma transformação estrutural e, por isso mesmo, deveria ser gradual e lenta em sua cultura e sociedade, através da relação da mediação entre mídia e outras estruturas sociais. Contudo, essa assimilação acontece, justamente, num momento de transição de ajuste cultural e de apropriação social 
para a sua convivência e salvaguarda na relação com a cultura dominante do "homem civilizado".

Nos meios tradicionais - e para a sociedade brasileira - os Paiter-Suruí estavam mudos e sem perspectivas. As ferramentas, sua utilização, o recurso da mídia para sua visibilidade e a inserção do local para o global projetou a luta dos Paiter-Suruí. Com o recurso que a apropriação social Ihes permitiu no contato tecnológico, despontou um novo tempo e a estruturação de novas relações e possibilidades.

Esses eram padrões que não pertenciam ao arcabouço cultural PaiterSuruí, porém sua absorção, apreensão e convivência na sociedade em rede passam a ser fator crucial para garantir a sua preservação. A utilização das novas mídias, sua estrutura e consequente produção de novas relações estabelecem uma nova perspectiva para a etnia. Ao invés de lutar com arcos e flechas para preservar sua cultura, os indígenas possuem novas estratégias e ferramentas para sua resistência na sociedade da informação.

Suas narrativas, mitos, ritos, lendas, canções e poemas continuam a existir. A apropriação social não substituiu sua tradição oral. Ampliaram-se as expressões e a mídia digital passou a ser uma de suas apresentações. A preservação da cultura continua sendo pela oralidade, porém 0 compartilhamento virtual com outras culturas os anuncia ao mundo. Suas fronteiras se estenderam para além do território real, a sua expansão virtual lhes permitiu visibilidade e que, agora, sua voz ecoe.

\section{REFERÊNCIAS}

ALISSON, E. Desmatamento na Amazônia está prestes a atingir limite irreversível. 2018. Disponível em: http://agencia.fapesp.br/desmatamento-naamazonia-esta-prestes-a-atingir-limite-irreversivel/27180/. Acesso em 20 out 2018.

ASSMANN, A. Espaços da recordação: formas e transformações da memória cultural. Campinas: UNICAMP, 2011.

CALVET, L. Tradição oral \& tradição escrita. São Paulo: Parábola Editorial, 2011. 
COORDENAÇÃO DAS ORGANIZAÇÕES INDÍGENAS DA AMAZÔNIA BRASILERIA. Corredor Tupí Mondé movimento indígena se articula na região. Manaus, 4 jul. 2011. Disponível em:

http://www.coiab.com.br/coiab.php?dest=show\&back=noticia\&id=741\&tipo=N\&p agina=4. Acesso em 23 out. 2018.

HJARVARD, S. A midiatização do Habitus: o caráter social de um novo individualismo. In: HJARVARD, S. A midiatização da cultura e da sociedade. São Leopoldo: Unisinos, 2014.

HJARVARD, S. Da mediação à midiatização: a institucionalização das novas mídias. Parágrafo, v. 3, n. 2, jul./dez. 2015.

LE GOFF, J. História e memória. Campinas: UNICAMP, 1990.

MELO, K. C.; SILVA, A. de A.; SURUÍ, A. N. Os Paiter Suruí e o Mapimaí: a representação como "marcador territorial". ACTA Geográfica, v. 9, n. 20, 2015. Disponível em: https://revista.ufrr.br/actageo/article/view/1999. Acesso em: 25 out. 2018.

DICIONÁRIO AMBIENTAL ((O))ECO. O que é Evapotranspiração. 2014. Disponível em: http://www.oeco.org.br/dicionario-ambiental/28768-o-que-eevotranspiracao. Acesso em: 10 out. 2018.

PUCCI, M. D. A Arte oral: Paiter Suruí de Rondônia. 2009. 364 f. Dissertação (Mestrado em Ciências Sociais) - Pontifícia Universidade Católica de São Paulo, 2009. Disponível em: https://tede2.pucsp.br/handle/handle/4066. Acesso em: 20 out. 2018.

RIBEIRO, F. Memória, Informação e Ciência da Informação: relações e interdependências. In: OLIVEIRA, E. B. de; RODRIGUES, G. M. (Orgs.).

Memória: interfaces no campo da informação. Brasília: UnB, 2019. p. 111-137.

ROMERO, Z. M. Os Paiter Suruí: do arco e flechas ao uso das tecnologias do século XXI. In: Congresso Internacional de História, Anais [...], 2013.

Disponível em: http://www.cih.uem.br/anais/2013/trabalhos/118 trabalho.pdf. Acesso em: 20 dez. 2019.

TRUBILIANO, C. A. B.; FERREIRA, L. M. R. Apontamentos sobre educação, cultura e etnoconhecimentos Paiter Suruí. Revista Educação e Cultura Contemporânea, v. 15, n. 40, 2018. Disponível em: http://periodicos.estacio.br/index.php/reeduc/article/viewArticle/1371. Acesso em: 10 nov. 2018.

\section{THE PAITER-SURUÍ AND THE SOCIAL APPROPRIATION OF TECHNOLOGY, INFORMATION AND COMMUNICATION: FROM ORAL MEMORY TO}




\title{
DIGITAL MEMORY
}

\begin{abstract}
Introduction: this work is based on a historical-sociological approach, with the intention of using the conceptual dialogue of the social sciences with the informational concepts in the reorganization of the culture of the Paiter-Suruí ethnic group in its relation with contemporary culture and the digital world. Far beyond cultural exchanges and impositions, the imperative of acquisition through the social appropriation of technologies, communication and information (ICT) induced the Paiter-Suruí to a cultural adaptation and resistance to the network society. Objective: the paper proposes to present the process of transition from oral memory to digital memory. Methodology: This is a case study with documentary survey of the period of 2006: Paiterey Garah Indigenous Land Management Plan, Ethnozoneament and Oral Transcriptions to the present day of the Paiter-Suruí partnership with Google Inc., bibliographical review of information science, dialoguing with the social sciences. Results: the research reveals the process of cultural transition through social appropriation, reflecting the consequences, pros, cons and perspectives. Conclusions: social appropriation did not replace Paiter-Suruí's oral tradition. Their expressions extended and the digital media became one of their presentations. The preservation of culture continues to be oral, but virtual sharing with other cultures announces them to the world. Their frontiers expanded beyond the real territory, their virtual expansion allowed them visibility and that, now, their voice echoes.
\end{abstract}

Keywords: Social appropriation. Culture. Digital Memory. Oral Memory. Technology, Communication and Information (ICT).

\section{LOS PAITER-SURUÍ Y LA APROPIACIÓN SOCIAL DE LA TECNOLOGÍA, INFORMACIÓN Y COMUNICACIÓN: DE LA MEMORIA ORAL PARA LA MEMORIA DIGITAL}

\begin{abstract}
RESUMEN
Introducción: este trabajo se basó en un enfoque histórico-sociológico, con el intento de emplear el diálogo conceptual de las ciencias sociales con los conceptos informacionales en la reorganización de la cultura de la etnia Paiter-Suruí en su relación con la cultura contemporánea y el mundo digital. Mucho más allá de los intercambios e imposiciones culturales, el imperativo de la adquisición por la apropiación social de las tecnologías, comunicación e información (TIC) oportunizó adaptación y resistencia cultural de los Paiter-Suruí a la sociedad en red. Objetivo: el trabajo propone presentar el proceso de transición de la memoria oral a la memoria digital. Metodología: estudio de caso con levantamiento documental del período de 2006: Plan de Gestión de la Tierra Indígena Paiterey Garah, Etnozoneamiento y Transcripciones Orales hasta los días actuales de la asociación de los Paiter-Suruí con Google Inc., revisión bibliográfica de la ciencia de la información dialogando con las Ciencias Sociales. Resultados: la investigación revela el proceso de transición cultural por la apropiación social, refleja sus consecuencias pros, contra y perspectivas. Conclusiones: la apropiación social no sustituyó a su tradición oral. Se ampliaron las expresiones, los medios digitales, pasó a ser una de sus presentaciones. La preservación de la cultura sigue siendo por la
\end{abstract}

Inf. Inf., Londrina, v. 24, n. 3, p. 289 - 310, set./dez. 2019. 
oralidad, pero el compartir virtual con otras culturas los anuncia al mundo. Sus fronteras se extendieron más allá del territorio real, su expansión virtual les permitió visibilidad y que su voz resonara.

Descriptores: Apropiación Social. Cultura. Memoria Digital. Memoria Oral. Tecnología, Comunicación e Información (TIC). 